\title{
Tropical cooling in the case of stratospheric sudden warming in January 2009: focus on the tropical tropopause layer
}

\author{
K. Yoshida ${ }^{1,2}$ and K. Yamazaki ${ }^{3}$ \\ ${ }^{1}$ Graduate School of Environmental Science, Hokkaido University, Sapporo, Japan \\ ${ }^{2}$ Morioka Meteorological Observatory, Morioka, Japan \\ ${ }^{3}$ Faculty of Environmental Earth Science, Hokkaido University, Sapporo, Japan
}

Received: 6 January 2011 - Published in Atmos. Chem. Phys. Discuss.: 21 January 2011

Revised: 9 June 2011 - Accepted: 18 June 2011 - Published: 5 July 2011

\begin{abstract}
Temperature changes in the tropics, especially in the tropical tropopause layer, are investigated at the time of a major stratospheric sudden warming (SSW) event that started on about 16 January 2009. During the SSW, the temperature in the tropical upper stratosphere declined and the cold anomaly propagated downward, while the tropics between 150 and $100 \mathrm{hPa}$ started to cool from 18 January, prior to a temperature drop at $70 \mathrm{hPa}$. We performed thermodynamical and dynamical analyses with ERA-Interim data. During the SSW event, the tropical stratosphere was cooled by upwelling, and the upwelling was induced by wave forcing in the northern extratropical stratosphere. However, the stratospheric wave forcing generated only weak upwelling in the tropics below $100 \mathrm{hPa}$. During the cooling period at around 18 January, tropical ascent was the main contributor to cooling of the tropics between 150 and $100 \mathrm{hPa}$. Subsequently, vertical convergence of the vertical heat flux, which is closely tied to the convection structure, resulted in a gradual decrease in temperature within the tropical uppermost troposphere. Waves that had same source region with the upwardpropagating waves that caused the SSW event, propagated from Alaska to the tropics of eastern South America and eastern Africa at around $100 \mathrm{hPa}$, and dissipated in these areas; the associated wave forcing drove the tropical ascent between 150 and $100 \mathrm{hPa}$.
\end{abstract}

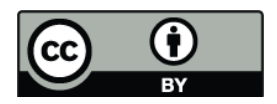

Correspondence to: K. Yoshida (kohei@ees.hokudai.ac.jp)

\section{Introduction}

The tropical tropopause layer (TTL; defined here as the tropics between 150 and $70 \mathrm{hPa}$ ) is an important region in stratospheric physics and chemistry because of its role as a gateway to the stratosphere. The coldness in the TTL, especially in the cold-point tropopause (which is the coldest region in the TTL), controls the large-scale distribution of water vapor in the stratosphere by dehydration of the air entering the stratosphere (Holton and Gettleman, 2001; Hatsushika and Yamazaki, 2003; Fueglistaler et al., 2005). Thus, spatial and temporal variations in the TTL have been examined in many previous studies (e.g., Highwood and Hoskins, 1998; Fueglistaler et al., 2009).

The TTL temperature is affected by processes in the troposphere and in the stratosphere, especially through the circulation. Mean stratospheric poleward flow, which is driven by the dissipation of vertically propagating Rossby and gravity waves, induces upwelling in the tropics and downwelling in the extratropics to conserve mass (the so-called BrewerDobson circulation) (Yulaeva et al., 1994; Haynes et al., 1991; Plumb and Eluszkiewicz, 1999). The zonal mean temperature in the TTL is considered to be controlled by wave forcing of the extratropical stratosphere, which is referred to as the "stratospheric pump" (Holton et al., 1995). Tropical waves also drive a residual circulation in the TTL. Kerr-Munslow and Norton (2006) suggested that dissipation of quasi-stationary waves in the upper troposphere and lower stratosphere generated by deep convection induces upwelling in the TTL, resulting in a reduction in TTL temperature. Based on this result and model calculations, Norton (2006) reported that seasonally varying tropical Rossby

Published by Copernicus Publications on behalf of the European Geosciences Union. 
waves generate an annual cycle in upwelling and therefore also in temperature. As an effect other than upwelling, Yoshida and Yamazaki (2010) suggested vertical convergence of vertical heat flux $\overline{w^{\prime} \theta^{\prime}}$ (see Sect. 2.2 for detail), which is closely tied to tropical convection structure, plays a role in heat budget in the TTL.

Stratospheric sudden warming (SSW) is one of the most dramatic phenomena in the stratospheric atmosphere. The strong planetary-scale waves induce violent meridional circulation in the winter hemisphere of the stratosphere (Matsuno, 1971). The relationship between the tropical troposphere and the SSW has been discussed in several studies. Kodera (2006) suggested that meridional circulation change associated with the SSW in Arctic regions produces a lower temperature in the equatorial lower stratosphere, which leads to a seesaw pattern of convective activity, an enhancement of convective activity near the equatorial Southern Hemisphere $\left(10^{\circ} \mathrm{S}\right.$-equator) and a suppression in the tropics of the Northern Hemisphere $\left(5^{\circ} \mathrm{N}-15^{\circ} \mathrm{N}\right)$. Kuroda (2008) suggested that tropical convection tends to be enhanced during SSW due to nonuniform meridional propagation of the planetary wave around the tropopause, associated with upward propagation of the planetary wave to the stratosphere. These phenomena may influence the TTL.

A strong SSW event occurred in the second half of January 2009. Manney et al. (2009) provided an overview of dynamics and transport during the 2009 SSW, based on observations by the Aura Microwave Limb Sounder (AMLS). The occurrence of very large wave-2 during the SSW in 2009 is consistent with vortex split. Harada et al. (2010) reported that the total amount of upward Eliassen-Palm (EP) flux for wave 2 was the strongest since the boreal winter of 1978/79, and the remarkable development of the upper tropospheric ridge over Alaska played an important role in the onset of SSW during January 2009.

The aim of this paper is to reveal how various factors (e.g., wave activity in the stratosphere, tropical convection, and meridional propagation of waves in the northern extratropics) affected the TTL in the case of the SSW event in January 2009. The remainder of this paper is organized as follows. Section 2 provides a description of the dataset and analysis methods. Section 3 shows the temperature structures as observed in the period of interest, and the associated thermodynamic budget calculated from ERA-Interim data. The nature of the forcing that causes the circulation in the TTL is evaluated in Sect. 4, and the structure of wave activity is described in Sect. 5. In Sect. 6, we consider the questions that arose in the preceding sections. Finally, the main results are summarized in Sect. 7.

\section{Data and methods}

\subsection{Data}

We used a 6-hourly dataset of European Centre for MediumRange Weather Forecasts (ECMWF) ERA-Interim (Simmons et al., 2006; Uppala et al., 2008). The period of analysis was from 1 December 2008 to 31 March 2009. The horizontal resolution of the ERA-Interim data is $1.5^{\circ} \times 1.5^{\circ}$ in latitude and longitude and it has 37 levels (see Sect. 2.6 for detailed levels in the upper troposphere and the stratosphere). Interpolated outgoing long-wave radiation (OLR) data were obtained from the Climate Diagnostic Center (CDC) of the National Oceanic and Atmospheric Administration (NOAA) (Liebmann and Smith, 1996). The data presented in this paper are smoothed using a 3-day running average, unless stated otherwise.

\subsection{Transformed Eulerian Mean equations}

To diagnose the zonal mean thermodynamic balance, quantitative analysis was performed by the transformed Eulerian mean (TEM) equations in log-pressure coordinates (see Andrews et al., 1987):

$$
\begin{aligned}
& \frac{\partial \bar{\theta}}{\partial t}=-\frac{\bar{v}^{*}}{a} \frac{\partial \bar{\theta}}{\partial \phi}-\bar{w}^{*} \frac{\partial \bar{\theta}}{\partial z}+\bar{Q}-\frac{1}{\rho_{0}} \frac{\partial}{\partial z}\left(\rho_{0} \overline{v^{\prime} \theta^{\prime}} \frac{\bar{\theta}_{\phi}}{a \bar{\theta}_{z}}\right) \\
&-\frac{1}{\rho_{0}} \frac{\partial}{\partial z}\left(\rho_{0} \overline{w^{\prime} \theta^{\prime}}\right) ; \\
& \bar{v}^{*} \equiv \bar{v}-\frac{1}{\rho_{0}} \frac{\partial}{\partial z}\left(\rho_{0} \frac{\overline{v^{\prime} \theta^{\prime}}}{\bar{\theta}_{z}}\right), \bar{w}^{*} \equiv \bar{w}+\frac{1}{a \cos \phi} \frac{\partial}{\partial \phi}\left(\cos \phi \frac{\overline{v^{\prime} \theta^{\prime}}}{\bar{\theta}_{z}}\right),
\end{aligned}
$$

where the overbar denotes the zonal mean, the prime is the departure from the zonal mean, subscripts denotes partial differentiation, $a$ is the radius of Earth, $\theta$ is potential temperature, $\phi$ is latitude, $\rho_{0}=\rho_{s} \exp (-z / H)$ is the reference density, $H=7050 \mathrm{~m}$ is the constant scale height, $\bar{Q}$ is diabatic heating, $\bar{v}^{*}$ is the residual mean meridional wind, and $\bar{w}^{*}$ is the residual mean vertical wind. The diabatic heating term is calculated from the residual in Eq. (1). The second term on the right-hand-side is vertical advection, and the last (fifth) term is vertical convergence of the vertical heat flux. The first and fourth terms on the right-hand-side can be neglected because they are minor compared with the other terms.

The EP flux was analyzed to evaluate eddy forcing in residual mean circulation (see Andrews et al., 1987):

$$
\begin{aligned}
& \boldsymbol{F} \equiv\left(0, F_{1}^{(\phi)}+F_{2}^{(\phi)}, F_{1}^{(z)}+F_{2}^{(z)}\right) \\
& F_{1}^{(\phi)} \equiv \rho_{0} a \cos \phi \frac{\partial \bar{u}}{\partial z} \frac{\overline{v^{\prime} \theta^{\prime}}}{\bar{\theta}_{z}}, F_{2}^{(\phi)} \equiv-\rho_{0} a \cos \phi \overline{u^{\prime} v^{\prime}} \\
& F_{1}^{(z)} \equiv \rho_{0} a \cos \phi \bar{\zeta} \frac{\overline{v^{\prime} \theta^{\prime}}}{\bar{\theta}_{z}}, F_{2}^{(z)} \equiv-\rho_{0} a \cos \phi \overline{u^{\prime} w^{\prime}}
\end{aligned}
$$


where $\bar{\zeta}=f-(a \cos \phi)^{-1}(\bar{u} \cos \phi)_{\phi}$ is the zonal mean absolute vorticity, $f$ is the Coriolis parameter, and $\boldsymbol{F}$ is EP flux. The total eddy forcing is represented by the divergence/convergence (westerly/easterly acceleration) of the EP flux.

\subsection{Wave activity flux}

To examine the behavior of the three-dimensional wave activity associated with the circulation in the midlatitude and tropics, we calculated the wave activity flux vector $\left(\boldsymbol{F}_{s}\right.$ vector) for quasi-geostrophic disturbance, as proposed by Plumb (1985).

The $\boldsymbol{F}_{s}$ vector can be given by

$$
\begin{aligned}
\boldsymbol{F}_{S} & =\left(\begin{array}{c}
F_{s}^{(\lambda)} \\
F_{S}^{(\phi)} \\
F_{S}^{(z)}
\end{array}\right) \\
& =p \cos \phi\left(\begin{array}{c}
v^{\prime 2}-\frac{1}{2 \Omega a \sin 2 \phi} \frac{\partial\left(v^{\prime} \Phi^{\prime}\right)}{\partial \lambda} \\
-u^{\prime} v^{\prime}+\frac{1}{2 \Omega a \sin 2 \phi} \frac{\partial\left(u^{\prime} \Phi^{\prime}\right)}{\partial \lambda} \\
\frac{2 \Omega \sin \phi}{S}\left[v^{\prime} T^{\prime}-\frac{1}{2 \Omega a \sin 2 \phi} \frac{\partial}{\partial \lambda}\left(T^{\prime} \Phi^{\prime}\right)\right]
\end{array}\right),
\end{aligned}
$$

where $S=\partial \hat{T} / \partial z+\kappa \hat{T} / H$ is the static stability (the caret indicates the regional average over the area between $15^{\circ} \mathrm{N}$ and $\left.75^{\circ} \mathrm{N}\right), p=$ pressure $/ 1000 \mathrm{hPa}$, and $\Omega$ is the Earth's rotation rate. Longitudinal integration of $\boldsymbol{F}_{s}$ corresponds to the EP flux in spherical quasi-geostrophic form.

\subsection{Diagnosis of upwelling}

To examine the response of residual mean circulation to external forcings, such as wave forcing and diabatic heating, the residual mean vertical wind was estimated by a diagnostic model using simplified TEM equations;

$\frac{\partial \bar{u}}{\partial t}-2 \Omega \mu \bar{v}^{*}=\bar{F}+\bar{X}$

$2 \Omega \mu \bar{u}=-\frac{1}{a} \sqrt{1-\mu^{2}} \frac{\partial \bar{\Phi}}{\partial \mu}$,

$\frac{\partial \bar{\Phi}}{\partial p}=-\frac{R \bar{T}}{p}$,

$\frac{1}{a} \frac{\partial \sqrt{1-\mu^{2}} \bar{v}^{*}}{\partial \mu}+\frac{\partial \bar{\omega}^{*}}{\partial p}=0$,

$\frac{\partial \bar{T}}{\partial t}-\Gamma \bar{\omega}^{*}=\bar{Q}+\bar{E}$,

where $\bar{\omega}^{*}$ is the residual mean vertical wind in pressure coordinates, $\bar{F}$ is divergence of the EP flux, $\bar{X}$ is eastward residual forcing, $\bar{E}$ is vertical convergence of the vertical heat flux, $\Gamma=-\partial T_{0} / \partial p+\kappa T_{0} / p$ is static stability, $R$ is the ideal gas constant, and $\mu$ is sine latitude. The eastward residual forcing term is calculated from the residual in Eq. (7). Except for the terms of the residual mean circulation, EP flux divergence, and vertical convergence of vertical heat flux, Eqs. (7-11) are essentially the same as those used by Plumb (1982), Haynes and Shepherd (1989), and Kuroda and Kodera (2004).

We can obtain a diagnostic equation for $\bar{\omega}^{*}$ by using Eqs. (7-11), as follows:

$$
\begin{aligned}
\frac{\partial}{\partial \mu}\left[\frac{1-\mu^{2}}{\mu^{2}} \frac{\partial \bar{\omega}^{*}}{\partial \mu}\right]+\frac{4 \Omega^{2} a^{2} p}{R \Gamma} \frac{\partial^{2} \bar{\omega}^{*}}{\partial p^{2}} \\
=\frac{2 \Omega a p}{R \Gamma} \frac{\partial^{2}}{\partial \mu \partial p}\left[\frac{\sqrt{1-\mu^{2}}}{\mu}(\bar{F}+\bar{X})\right] \\
-\frac{1}{\Gamma} \frac{\partial}{\partial \mu}\left[\frac{1-\mu^{2}}{\mu^{2}}\left(\frac{\partial \bar{Q}}{\partial \mu}+\frac{\partial \bar{E}}{\partial \mu}\right)\right] .
\end{aligned}
$$

Equation (12) is easily solved if all variables are expanded by a zero zonal wavenumber, zero frequency Hough function $\Theta_{n}(\mu)$, or its associated function $B_{n}(\mu)$ (e.g., Plumb, 1982; Haynes and Shepherd, 1989; Kuroda and Kodera, 2004), as follows:

$$
\begin{aligned}
\bar{\omega}^{*} & =\sum_{n} \omega_{n}^{*} \Theta_{n}(\mu), \bar{Q}=\sum_{n} Q_{n} \Theta_{n}(\mu), \bar{E}=\sum_{n} E_{n} \Theta_{n}(\mu), \\
\bar{F} & =\sum_{n} \hat{F}_{n} B_{n}(\mu), \bar{X}=\sum_{n} \hat{X}_{n} B_{n}(\mu)
\end{aligned}
$$

By using Eqs. (12) and (13), Eq. (12) is degenerated into an ordinary differential equation with respect to $p$ :

$$
\begin{aligned}
& \frac{4 \Omega^{2} a^{2} p}{R \Gamma} \frac{d^{2} \omega_{n}^{*}}{d p^{2}}+\varepsilon_{n} \omega_{n}^{*}=\frac{2 \Omega a p}{R \Gamma}\left(\frac{d \hat{F}_{n}}{d p}+\frac{d \hat{X}_{n}}{d p}\right) \\
& -\frac{\varepsilon_{n}}{\Gamma}\left(Q_{n}+E_{n}\right),
\end{aligned}
$$

where $\varepsilon_{n}$ is the $n$-th eigenvalue of the zonal Hough function. Equation (15) is a diagnostic equation; hence, $\omega_{n}^{*}$ is obtained by substituting the observed external forcings into the righthand-side of Eq. (15). Because of the linearity in Eq. (15), we can separately estimate the contribution of each external forcing and each forced region to residual mean vertical wind (hereafter, we describe these operations as a TEM model).

We can also include observed boundary values in Eq. (15) by treating it as an external forcing. The lower and upper boundary values of observed residual mean vertical velocity are expanded by using a Hough function, and these are substituted into differential terms. Treating the differential terms as a kind of external forcing, the effect of observed boundary values can be considered in the TEM model; however, it should be noted that the observed boundary values may have errors related to topography. 


\subsection{Refractive index}

The square of the refractive index, which characterizes the tendency for stationary wave propagation, as given by Matsuno (1970) and developed by Andrews et al. (1987) and $\mathrm{Hu}$ and Tung (2002), is presented in spherical quasi-geostrophic form as follows:

$n_{k}^{2}(\phi, z)=\frac{\bar{q}_{\phi}}{\bar{u}}-\left(\frac{k}{a \cos \phi}\right)^{2}-\left(\frac{f}{2 \mathrm{NH}}\right)^{2}$,

where

$\bar{q}_{\phi}=\frac{2 \Omega}{a} \cos \phi-\frac{1}{a^{2}}\left[\frac{(\bar{u} \cos \phi)_{\phi}}{\cos \phi}\right]_{\phi}-\frac{f^{2}}{\rho_{0}}\left(\rho_{0} \frac{\bar{u}_{z}}{N^{2}}\right)_{z}$

is the meridional gradient of the mean potential vorticity and $k$ is the zonal wavenumber. Stationary waves with zonal wavenumber $k$ are able to propagate in regions where $n_{k}^{2}>0$ and are refracted toward a region of larger $n_{k}^{2}$.

\subsection{Vertical interpolation}

To yield the detailed vertical structure, vertical spline interpolation was performed in the upper troposphere and the stratosphere. We interpolated onto the following pressure levels: [175], 162.5, [150], 137.5, [125], 112.5, [100], 90, 80, [70], 60, [50], 40, [30], [20], 15, [10], [7], 6, [5], 4, [3], $2.5,[2], 1.5,1.2$, and $[1] \mathrm{hPa}$, where brackets denote original pressure levels. To avoid analytical error, the interpolation was performed after eddy terms had been calculated at original pressure levels.

\section{Temperature changes and heat budget}

Figure 1 shows time-height sections of the zonal-mean temperatures averaged over $70^{\circ} \mathrm{N}-90^{\circ} \mathrm{N}$ and $10^{\circ} \mathrm{S}-10^{\circ} \mathrm{N}$, and their anomalies calculated from the mean of the period from 1 December 2008 to 31 March 2009. A rapid increase in $10 \mathrm{hPa}$ temperature occurs in the Arctic region from $18 \mathrm{Jan}-$ uary, and the warm anomaly propagates downward (Fig. 1a). At the same time, the $10 \mathrm{hPa}$ temperature in the tropics shows a drastic decline and the cold anomaly propagates downward (Fig. 1b). Around 26 January, rate of the temperature change reaches its peak at $70 \mathrm{hPa}$ (maximum rate of temperature decrease, $-0.34 \mathrm{~K} \mathrm{day}^{-1}$ ). The temperature drop between 150 and $125 \mathrm{hPa}$ occurs around 18 January, which is larger than that at $70 \mathrm{hPa}$ (maximum rate of temperature decrease at $125 \mathrm{hPa},-0.4 \mathrm{~K} \mathrm{day}^{-1}$ ). There is no clear relationship between the temperature anomalies in the tropical stratosphere and in the tropical troposphere. In the stratosphere we see the usual signature of an evolving SSW from January through early March. In the troposphere the temperature anomalies oscillate on a much shorter time scale that appears unrelated to what transpires above $100 \mathrm{hPa}$. To identify the cause of the temperature change in the tropics, we performed a heat budget analysis.

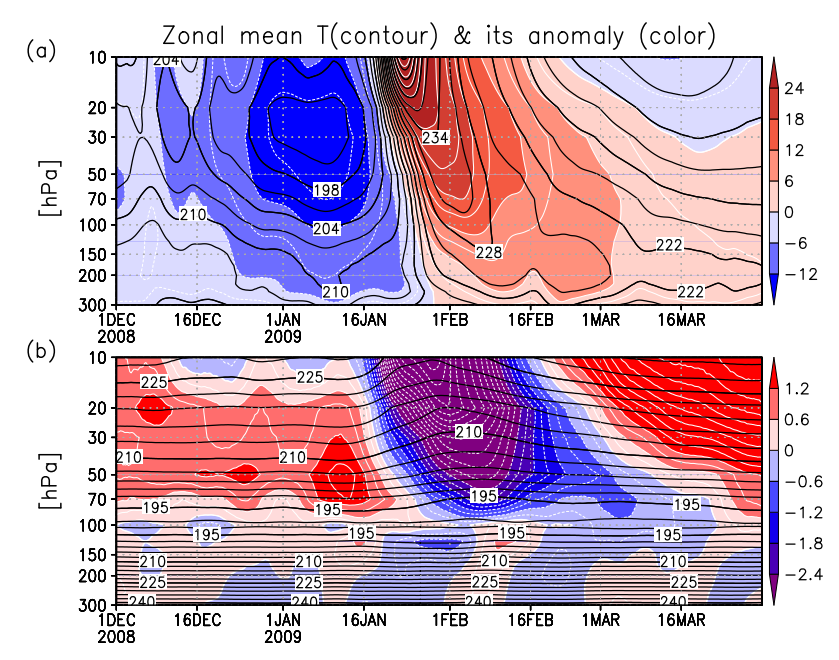

Fig. 1. Time-altitude section of zonal mean temperature (K; contours) and its anomaly (K; color shading) averaged over (a) $70^{\circ} \mathrm{N}-$ $90^{\circ} \mathrm{N}$ and (b) $10^{\circ} \mathrm{S}-10^{\circ} \mathrm{N}$. The anomaly is the deviation from the 4-month (DJFM) mean. White contours show the anomaly of the zonal mean temperature, with contour intervals of $3 \mathrm{~K}$ in (a) and $0.3 \mathrm{~K}$ in (b). Black contour interval is $3 \mathrm{~K}$. Data are smoothed using a 5-day running average.

Figure 2a-e compares the zonal mean temperature and the residual mean vertical wind at various layers from 150 to $10 \mathrm{hPa}$ in the tropics, and Fig. $2 \mathrm{f}-\mathrm{j}$ shows the major terms in the TEM thermodynamic equation at the same altitudes as those in Fig. 2a-e. The upward flow results in a marked decrease in $10 \mathrm{hPa}$ temperature around 19 January (Fig. 2a), and vertical advection has a strong influence on the $10 \mathrm{hPa}$ potential temperature during this period (Fig. 2f). The temperature change due to vertical advection at $70 \mathrm{hPa}$, which achieves a minimum value on 26 January, is weaker than that at $10 \mathrm{hPa}$ (Fig. 2b, g). There is no evidence of large rate of temperature changes at $100 \mathrm{hPa}$ after 26 January (Fig. 2c). On 18 January, the temperature declines in response to vertical advection between 150 and $100 \mathrm{hPa}$ (Fig. 2c-e, h-j). These changes are not synchronized with those at $70 \mathrm{hPa}$. In addition, after 18 January, cold temperature anomalies between 150 and $125 \mathrm{hPa}$ persist for $1-2$ weeks under the influence of vertical convergence of the vertical heat flux (Fig. 2i, j). This aspect is discussed in Sect. 6. These observations indicate that the temperature changes between 150 and $100 \mathrm{hPa}$ appear not to be caused by vertical advection associated with the stratospheric process, although the cooling is caused mainly by vertical advection. In Sects. 4 and 5, we examine the forcings that induced tropical ascent between 150 and $100 \mathrm{hPa}$. 

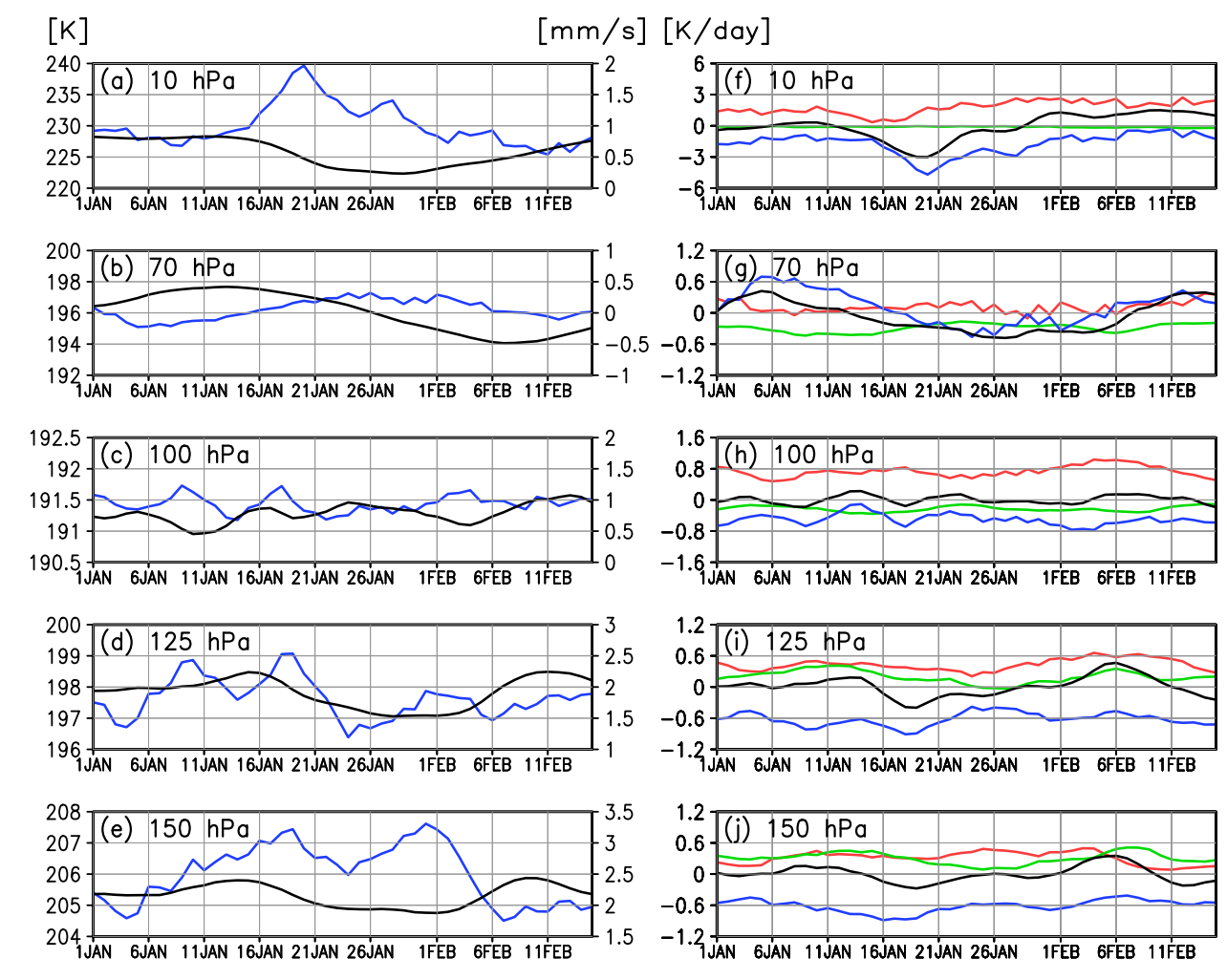

Fig. 2. Time series of (left) zonal-mean temperature (K; black lines), residual mean vertical wind ( $\mathrm{mm} \mathrm{s}^{-1}$; blue lines), and (right) major terms in the transformed Eulerian mean (TEM) thermodynamic equation averaged over $10^{\circ} \mathrm{S}-10^{\circ} \mathrm{N}\left(\mathrm{K} \mathrm{d}{ }^{-1}\right) .(\mathbf{a}, \mathbf{f}) 10 \mathrm{hPa},(\mathbf{b}, \mathbf{g}) 70 \mathrm{hPa},(\mathbf{c}$, h) $100 \mathrm{hPa},(\mathbf{d}, \mathbf{i}) 125 \mathrm{hPa}$, and $(\mathbf{e}, \mathbf{j}) 150 \mathrm{hPa}$. The terms in the TEM thermodynamic equation consist of potential temperature change (black lines), vertical advection (blue lines), vertical convergence of vertical heat flux (green lines), and diabatic heating (red lines). Other terms are not shown. Data are smoothed using a 5-day running average.

\section{Tropical upwelling generated by external forcing}

To evaluate what and where forcing induces upwelling in the tropics, we estimate the residual mean vertical wind generated by external forcing, using the TEM model introduced in Sect. 2. The vertical flow is estimated for each forcing and each region. The external forcing consists of EP flux divergence, eastward residual forcing, diabatic heating, and vertical heat flux convergence. The forced regions are classified into seven regions (Table 1). We compare the observed and calculated residual mean vertical wind.

Figure 3 shows the residual mean vertical wind in the tropics between 200 and $10 \mathrm{hPa}$. When the boundary value is zero at the top and bottom, although diagnosed tropical upwelling is smaller than observed in the TTL, its temporal variation is similar through January (Fig. 3a and b). Global forcing above $80 \mathrm{hPa}$ generates most of the tropical upwelling above $70 \mathrm{hPa}$ (Fig. 3c). Global forcing below $90 \mathrm{hPa}$ induces time changes in the tropical upwelling below $100 \mathrm{hPa}$ (Fig. 3d). Although stratospheric forcing associated with SSW appears to drive tropical upwelling above $70 \mathrm{hPa}$, it does not drive tropical upwelling below $100 \mathrm{hPa}$ strongly.
Table 1. List of regions where external forcings are imposed.

\begin{tabular}{ll}
\hline Forced region & Forced region in detail \\
\hline All regions & $90^{\circ} \mathrm{S}-90^{\circ} \mathrm{N}, 975-1.2 \mathrm{hPa}$ \\
Global stratosphere & $90^{\circ} \mathrm{S}-90^{\circ} \mathrm{N}, 80-1.2 \mathrm{hPa}$ \\
Northern hemispheric stratosphere & $\mathrm{EQ}-90^{\circ} \mathrm{N}, 80-1.2 \mathrm{hPa}$ \\
Southern hemispheric stratosphere & $90^{\circ} \mathrm{S}-\mathrm{EQ}, 80-1.2 \mathrm{hPa}$ \\
Global troposphere & $90^{\circ} \mathrm{S}-90^{\circ} \mathrm{N}, 975-90 \mathrm{hPa}$ \\
Northern hemispheric troposphere & $\mathrm{EQ}-90^{\circ} \mathrm{N}, 975-90 \mathrm{hPa}$ \\
Southern hemispheric troposphere & $90^{\circ} \mathrm{S}-\mathrm{EQ}, 975-90 \mathrm{hPa}$ \\
\hline
\end{tabular}

Figure 4 shows the residual mean vertical wind in the tropics averaged between 50 and $20 \mathrm{hPa}$. When the boundary value is zero at the top and bottom, although the diagnosed upwelling is smaller than observed, its temporal variation is similar (gray line in Fig. 4a) to the observed one. When the observed boundary values are included, the estimated vertical flow resembles the observed flow, although it overestimates by approximately $0.2 \mathrm{~mm} \mathrm{~s}^{-1}$. The estimated vertical flow from global forcing above $80 \mathrm{hPa}$ (blue solid line 


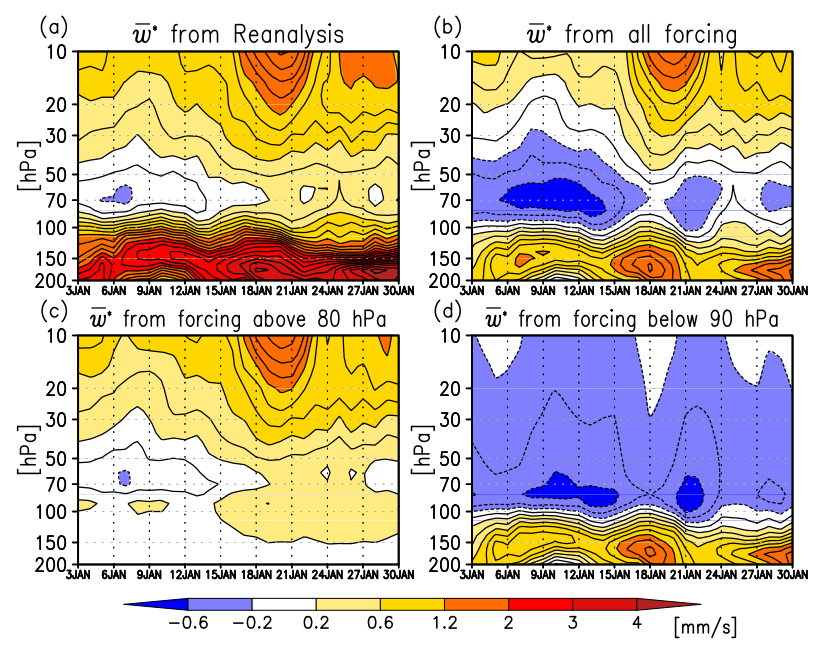

Fig. 3. Time-altitude section of the residual mean vertical wind $\left(\mathrm{mm} \mathrm{s}^{-1}\right.$; color shadings and contours) based on all forcing. (a) Observation, (b) forcing in all regions, (c) forcing in the global stratosphere, and (d) forcing in the global troposphere. Contour interval is $0.2 \mathrm{~mm} \mathrm{~s}^{-1}$. See Table 1 for detail.

in Fig. 4) shows good agreement with the observed temporal variation. In contrast, the vertical flow estimated from global forcing below $90 \mathrm{hPa}$ (green line in the figure) indicates minor variability and is not in good agreement with observed variations. The global forcing above $80 \mathrm{hPa}$ induces the bulk of the temporal variation between 50 and $20 \mathrm{hPa}$. Furthermore, in the case of northern hemispheric forcing above $80 \mathrm{hPa}$, the estimated vertical flow performs pretty well in reconstructing the observed temporal variation (Fig. 4b; blue dashed line). Thus, the TEM model performs well in reproducing the temporal variations, and the northern hemispheric forcing above $80 \mathrm{hPa}$ generates most of the tropical upwelling in the stratosphere. In the northern hemispheric forcing above $80 \mathrm{hPa}$, divergence of the EP flux (especially $F_{1}^{(z)}$ ) controls tropical ascent in the stratosphere (not shown).

Figure 5a compares the observed residual mean vertical wind with that calculated from all external forcings in the TEM model, averaged between 150 and $100 \mathrm{hPa}$ in the tropics. The observed values show a maximum at $2.4 \mathrm{~mm} \mathrm{~s}^{-1}$ on 18 January, for the values estimated from forcings in both the all regions and the global region below $90 \mathrm{hPa}$. In addition, these estimated vertical flows are very similar to the observed variation throughout January, although underestimated. In the case of global forcing above $80 \mathrm{hPa}$, the tropical ascent is weakly driven during January (blue line in Fig. 5a). This finding indicates that tropical ascent is driven by global forcing below $90 \mathrm{hPa}$ throughout January (green solid line). Therefore, the stratospheric pump has only a minor influence on vertical flow between 150 and $100 \mathrm{hPa}$. The estimated values are systematically smaller than those observed. When the
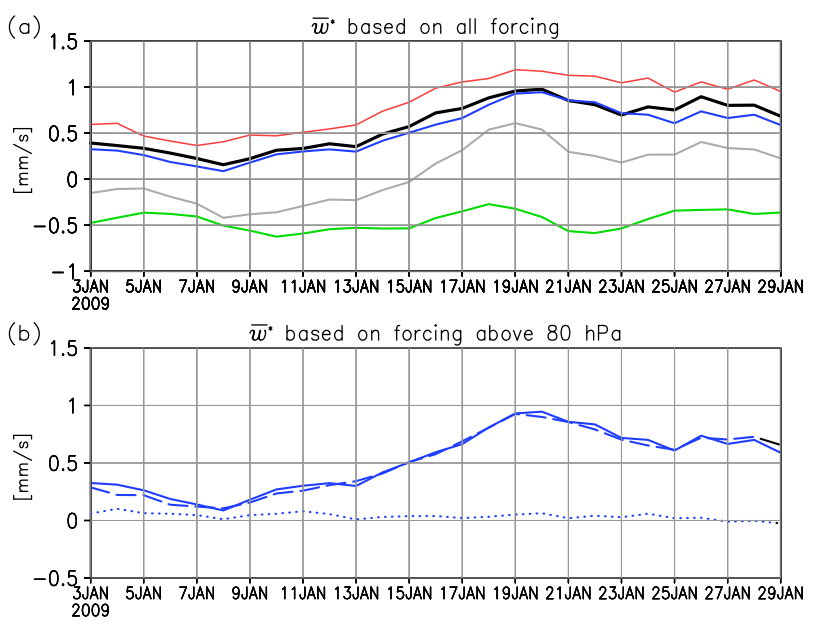

Fig. 4. Time series of residual mean vertical wind $\left(\mathrm{mm} \mathrm{s}^{-1}\right)$ in the tropics averaged over $50-20 \mathrm{hPa}$, based on all forcings. (a) Observations (black thick-solid line), forcing in the all regions (gray solid line), all regions including observed boundary values (red thinsolid line), global troposphere (green solid line), and global stratosphere (blue solid line). (b) Forcing in the global stratosphere (blue solid line; same as Fig. 4a), northern hemispheric stratosphere (blue dashed line), and southern hemispheric stratosphere (blue dotted line). See Table 1 for details.

observed boundary values are included, the mean estimated value is closer to the mean observed value, but the estimated temporal variation differs slightly from that observed.

Figure $5 \mathrm{~b}$ compares the residual mean vertical velocity generated by global tropospheric forcing with that by forcings below $90 \mathrm{hPa}$ in the Southern and Northern Hemispheres. The maximum on 18 January is caused mainly by northern hemispheric forcing below $90 \mathrm{hPa}$ (green dashed line), and the second peak on 9 January is driven by southern hemispheric forcing below $90 \mathrm{hPa}$ (green dotted line). Thus, on 18 January, upwelling in the tropics between 150 and $100 \mathrm{hPa}$ is generated mainly by northern hemispheric forcing below $90 \mathrm{hPa}$.

Figure 6 compares the residual mean vertical wind calculated by each component of northern hemispheric forcing below $90 \mathrm{hPa}$. The mean vertical flow is driven by diabatic heating (purple dash-dotted line in the figure) and vertical divergence of $F_{2}^{(z)}$ (blue dotted line; associated with the vertical momentum flux $\overline{u^{\prime} w^{\prime}}$ ). Because of small temporal variation in contribution of the diabatic heating, diabatic upwelling balanced with infrared radiative relaxation did not have large impact on the temporal variation of tropical upwelling between 150 and $100 \mathrm{hPa}$. Temporal variations in vertical flow are mainly forced by vertical divergence of $F_{1}^{(z)}$ (red dashed line), especially around 18 January. Temporal variations in the divergences of $F_{2}^{(\phi)}$ and $F_{2}^{(z)}$ influence the upward flow around 17 January and 15 January, respectively. In fact, $F_{1}^{(z)}$ 
(a)

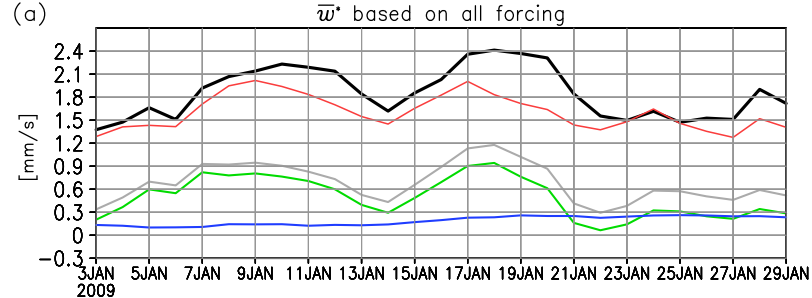

(b)

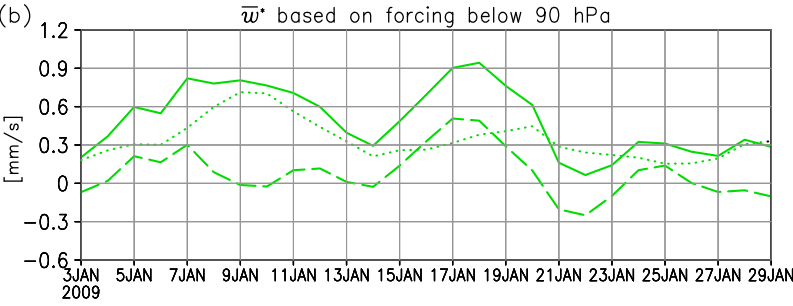

Fig. 5. As for Fig. 4, except for residual mean vertical wind $\left(\mathrm{mm} \mathrm{s}^{-1}\right)$ in the tropics averaged over $150-100 \mathrm{hPa}$. (a) Observations (black thick-solid line), forcing in the all regions (gray solid line), all regions including observed boundary values (red thin-solid line), global troposphere (green solid line), and global stratosphere (blue solid line). (b) Forcing in the global troposphere (green solid line; same as a), northern hemispheric troposphere (green dashed line), and southern hemispheric troposphere (green dotted line). See Table 1 for details.

is the dominant contributor to the maximum in tropical ascent between 150 and $100 \mathrm{hPa}$ on 18 January. In the eddy forcing, $F_{1}^{(z)}$ makes the dominant contribution in both stratospheric forcing and tropospheric forcing on 18 January. It is necessary to examine tropical upwelling driven by stratospheric and tropospheric wave forcing, especially by $F_{1}^{(z)}$ in the meridional plane.

Figure 7 shows anomalies of the estimated vertical flow from divergence of the EP flux above $80 \mathrm{hPa}$ and from vertical divergence of $F_{1}^{(z)}$ above $80 \mathrm{hPa}$ on 18 January. These anomalies are calculated from the mean value for January 2009. There is a small anomaly of stratospheric circulation due to very weak divergence of the EP flux in the Southern Hemisphere above $80 \mathrm{hPa}$ (Fig. 7a). A strong negative anomaly of EP flux divergence at high latitudes in the upper stratosphere generates a large anomaly in stratospheric circulation (Fig. 7b). A downwelling anomaly is induced at high latitudes and an upwelling anomaly is induced south of $50^{\circ} \mathrm{N}$. In the tropics and high latitudes, the anomaly of the residual mean vertical wind decays with decreasing altitude. The stratospheric wave forcing generates only a negligible tropical ascent $\left(<0.1 \mathrm{~mm} \mathrm{~s}^{-1}\right)$ below $70 \mathrm{hPa}$ on $18 \mathrm{Jan}$ uary. Southern hemispheric forcing above $80 \mathrm{hPa}$ due to the vertical divergence of $F_{1}^{(z)}$ is too weak to generate a strong anomaly of stratospheric circulation (Fig. 7c). Forced by the vertical divergence of $F_{1}^{(z)}$ in the northern hemispheric stratosphere, stratospheric circulation intensifies broadly, especially in the extratropical upper stratosphere, and weak

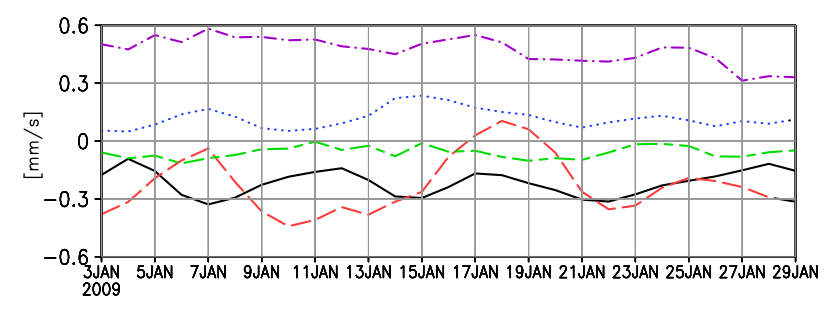

Fig. 6. Time series of residual mean vertical wind $\left(\mathrm{mm} \mathrm{s}^{-1}\right)$ in the tropics averaged over $150-100 \mathrm{hPa}$, based on each component of forcings in the northern hemispheric troposphere. Meridional divergence of second meridional component of the EP flux $F_{2}^{(\phi)}$ (black solid line), vertical divergence of first vertical component of the EP flux $F_{1}^{(z)}$ (red dashed line), vertical divergence of second vertical component of the EP flux $F_{2}^{(z)}$ (blue dotted line), eastward residual forcing $\bar{X}$ (green long-short dashed line), and diabatic heating $\bar{Q}$ (purple dash-dotted line). Estimated vertical wind by other forcings is not shown because of its small value. See Table 1 for details.
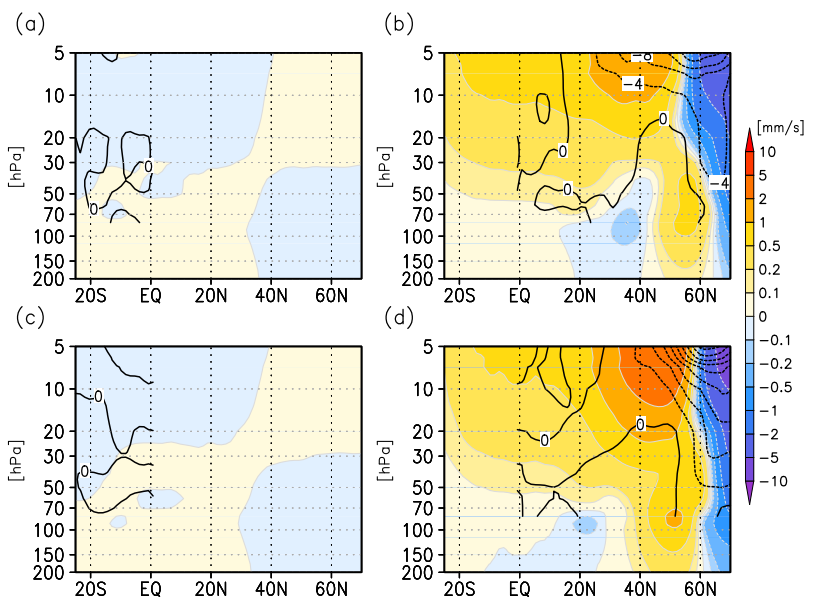

Fig. 7. (Top) Anomalies of the EP flux divergence (contours; $\mathrm{m} \mathrm{s}^{-1} \mathrm{~d}^{-1}$ ) and of the generated residual mean vertical wind using the EP flux divergence above $80 \mathrm{hPa}$ (color shading; $\mathrm{mm} \mathrm{s}^{-1}$ ) on 18 January 2009: (a) forcing in the southern hemispheric stratosphere and (b) northern hemispheric stratosphere. (Bottom) (c) and (d): same as (a) and (b) except for $F_{1}^{(z)}$ component only. These anomalies are the deviation from the mean value for January 2009. Contour interval is $4 \mathrm{~m} \mathrm{~s}^{-1} \mathrm{~d}^{-1}$. Divergences of the EP flux and $F_{1}^{(z)}$ below $90 \mathrm{hPa}$ are not shown. See Table 1 for details.

tropical ascent is generated in the lowermost stratosphere (Fig. 7d).

Figure 8 is the same as Fig. 7, but for forcing below $90 \mathrm{hPa}$. Convergence of the EP flux at around $7^{\circ} \mathrm{S}, 150 \mathrm{hPa}$ induces a positive anomaly of vertical flow in the tropics between 200 and $150 \mathrm{hPa}$ and at around $13^{\circ} \mathrm{S}, 125 \mathrm{hPa}$ (Fig. 8a). Eddy forcing in the southern hemispheric troposphere has a small effect on the TTL, but has a large effect below $150 \mathrm{hPa}$. Convergence of the EP flux at around $15^{\circ} \mathrm{N}$ in the upper 
(a)

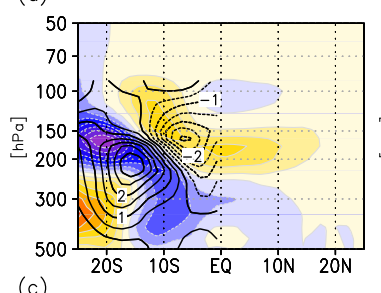

(c)

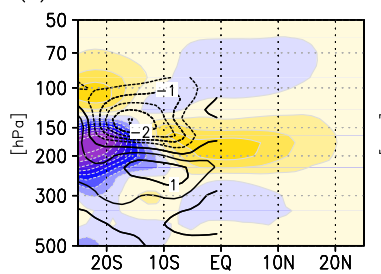

(b)

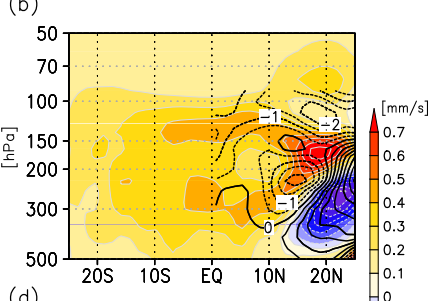

(d)

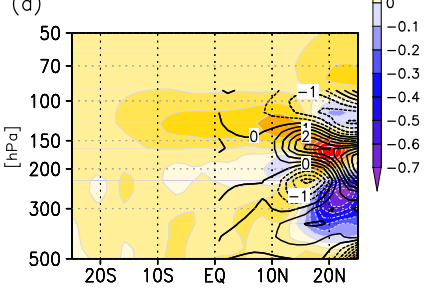

Fig. 8. As for Fig. 7, except for (left) forcing in the southern hemispheric troposphere and (right) northern hemispheric troposphere. Contour interval is $0.5 \mathrm{~m} \mathrm{~s}^{-1} \mathrm{~d}^{-1}$. Divergences of the EP flux and $F_{1}^{(z)}$ above $80 \mathrm{hPa}$ are not shown. See Table 1 for details.

troposphere and lower stratosphere generates a strong, broad upwelling anomaly in the tropics between 500 and $100 \mathrm{hPa}$ (Fig. 8b). In particular, remarkable tropical ascent is induced around 250 and $125 \mathrm{hPa}$ due to convergence of the EP flux.

The vertical convergence of $F_{1}^{(z)}$ at around $15^{\circ} \mathrm{N}, 100 \mathrm{hPa}$ generates a positive anomaly of the estimated vertical flow in the tropics between 150 and $100 \mathrm{hPa}$, while vertical convergence of $F_{1}^{(z)}$ around $15^{\circ} \mathrm{S}, 150 \mathrm{hPa}$ generates a positive anomaly of estimated vertical flow in the tropics at around $200 \mathrm{hPa}$ (Fig. 8c, d). Vertical convergence of $F_{1}^{(z)}$ drove large part on tropical upwelling anomaly between 150 and $100 \mathrm{hPa}$ (the other part driven by convergences of $F_{2}^{(\phi)}$ and $F_{2}^{(z)}$ ). Vertical convergences of $F_{1}^{(z)}$ at around $15^{\circ} \mathrm{N}, 100 \mathrm{hPa}$ and $15^{\circ} \mathrm{S}, 150 \mathrm{hPa}$ are the main factor in inducing tropical ascent at around 125 and $200 \mathrm{hPa}$, respectively. In next section, we investigate wave activity that caused the tropical upwelling in detail.

\section{Wave activity around the TTL}

\subsection{Eliassen-Palm flux}

Figure 9 shows latitude-height sections of the EP flux, its divergence, and the residual mean vertical wind. Before the SSW occurred, the vertical component of the EP flux is weak in the extratropical troposphere and stratosphere, and equatorward EP flux is weak in the subtropics of northern hemispheric upper troposphere (Fig. 9a, b). Thus, convergence of the EP flux is small around $15^{\circ} \mathrm{N}, 125 \mathrm{hPa}$. On 18 January, upward flow $\left(>4 \mathrm{~mm} \mathrm{~s}^{-1}\right.$ ) occurs broadly in the tropical upper troposphere (Fig. 9c). Tropical upwelling at $100 \mathrm{hPa}$ on 18 January is larger than that on 26 January, and it hap-
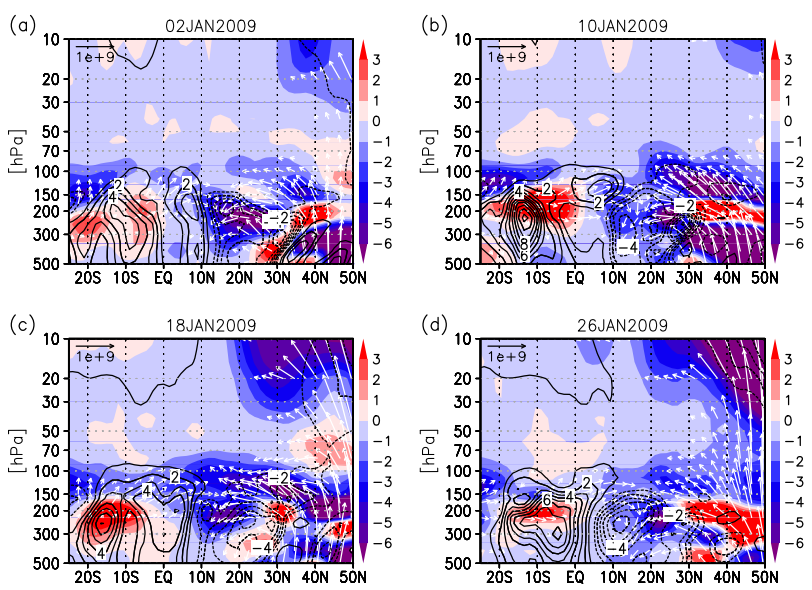

Fig. 9. Latitude-height section of the Eliassen-Palm (EP) flux (vectors; $\mathrm{m}^{3} \mathrm{~s}^{-2}$ ), the EP flux divergence (color shading; $\mathrm{m} \mathrm{s}^{-1} \mathrm{~d}^{-1}$ ), and the residual mean vertical wind (contours; $\mathrm{mm} \mathrm{s}^{-1}$ ) on (a) 2 January 2009, (b) 10 January 2009, (c) 18 January 2009, and (d) 26 January 2009. The EP flux is divided by the reference density, and the vertical component of the EP flux is multiplied by 300 .

pens before the peak of the SSW. Equatorward EP flux diverges vertically at around $20^{\circ} \mathrm{N}$, which causes convergence of the vertical component of the EP flux at around $200 \mathrm{hPa}$, $15^{\circ} \mathrm{N}$ and $100 \mathrm{hPa}, 15^{\circ} \mathrm{N}$. As shown in Fig. 8, convergence of the EP flux (especially $F_{1}^{(z)}$ ) around $15^{\circ} \mathrm{N}, 100 \mathrm{hPa}$ is the main contributor of tropical upwelling between 150 and $100 \mathrm{hPa}$. On 26 January, upward flow occurs in the tropics below $150 \mathrm{hPa}$. At the same time, the equatorward EP flux decreases in the subtropical troposphere (Fig. 9d). In these cases, wave propagation from the extratropical troposphere to the tropics is contributed by $F_{2}^{(\phi)}$ (associated with the meridional eddy momentum flux $\overline{u^{\prime} v^{\prime}}$ ) and $F_{1}^{(z)}$ (associated with the meridional eddy heat flux $\overline{v^{\prime} \theta^{\prime}}$ ) (not shown). Equatorward EP flux from the midlatitude troposphere appears to be coincident with upward EP flux in the midlatitude troposphere and stratosphere.

Figure 10 shows a time-altitude section of $F_{1}^{(z)}$ in midlatitudes and a time-latitude section of $F_{2}^{(\phi)}$ averaged over 125 and $100 \mathrm{hPa}$. From 10 January to 16 January, $F_{1}^{(z)}$ is amplified in the mid-latitude troposphere, which causes the SSW event (Fig. 10a). At the same time, the equatorward EP flux is intensified between 125 and $100 \mathrm{hPa}$ (Fig. 10b). These components of the EP flux $\left(F_{2}^{(\phi)}\right.$ and $\left.F_{1}^{(z)}\right)$ may be excited by the same wave source. To examine the wave activity in detail, it is necessary to investigate not only the meridional field but also the three-dimensional field.

\subsection{Three-dimensional wave activity flux}

To investigate the wave behavior in detail, we calculated the three-dimensional wave activity flux, as proposed by 
(a)

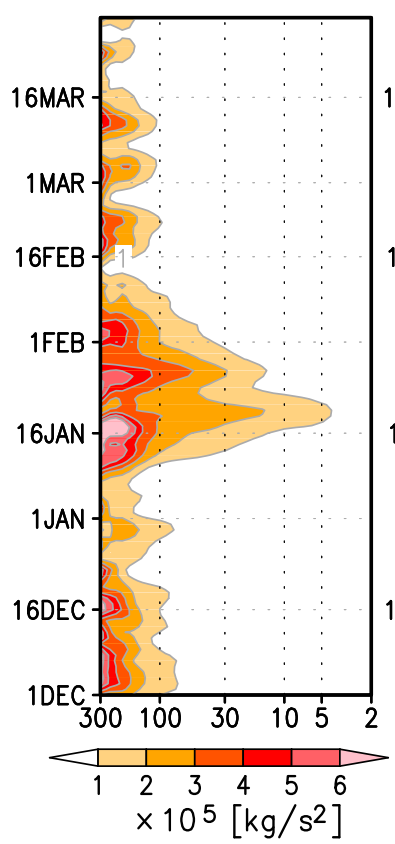

(b)

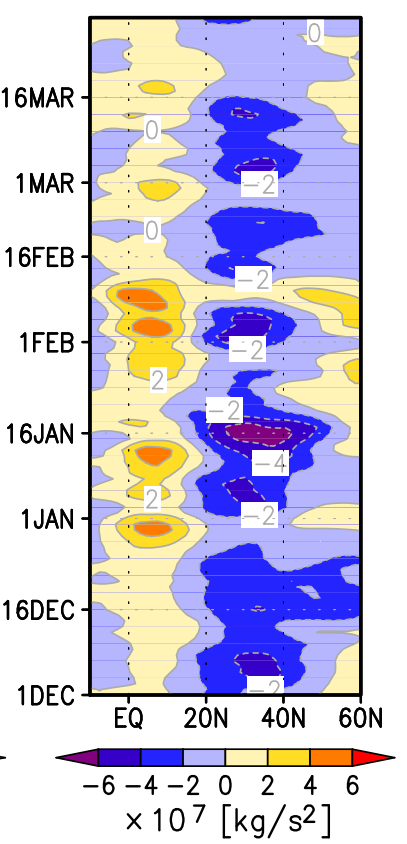

Fig. 10. (a) Time-altitude section of the first vertical component of the Eliassen-Palm (EP) flux $F_{1}^{(z)}$ averaged over $40^{\circ} \mathrm{N}-70^{\circ} \mathrm{N}$. (b) Time-latitude section of the second meridional component of the EP flux $F_{2}^{(\phi)}$ averaged between 125 and $100 \mathrm{hPa}$.

Plumb (1985). Figure 11 shows the time evolution of Plumb's (1985) wave activity flux $\boldsymbol{F}_{S}$ averaged between 125 and $100 \mathrm{hPa}$. On 12 January, the amplitude of wave activity flux is weak in the boreal mid-latitudes (Fig. 11a). On 15 January, wave activity over Alaska is blooming, and horizontal wave activity fluxes toward the tropical areas of the eastern Pacific and Atlantic are amplified (Fig. 11b). Due to downward wave activity flux around the northwestern Pacific, the longitudinal integration of vertical component of the wave activity flux, which corresponds to the vertical component of the EP flux, is negative around $10^{\circ} \mathrm{N}$. On 18 January, strong upward and southeastward wave activity fluxes are furthermore excited over Alaska (Fig. 11c). This upward wave activity flux apparently dominates the vertical component of the EP flux at high latitudes. In addition, the southeastward wave activity flux propagates toward the tropical eastern $\mathrm{Pa}-$ cific, and the eastward wave activity flux propagates farther toward the tropical eastern Atlantic. In the tropical eastern Pacific/Atlantic, the waves propagate upward. The upward wave activity flux in the tropical eastern Pacific and Atlantic has a large influence on the vertical component of the EP flux (not shown). Subsequently, the horizontal and vertical wave activity flux decays over Alaska, and upward wave activity flux in the tropical area of the eastern Pacific and Atlantic also diminishes (Fig. 11d).

(a) Wave Activity Flux 12JAN2009

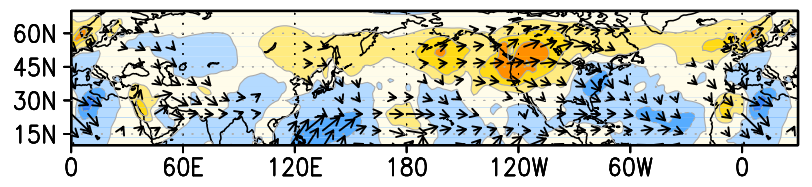

(b) Wave Activity Flux 15JAN2009

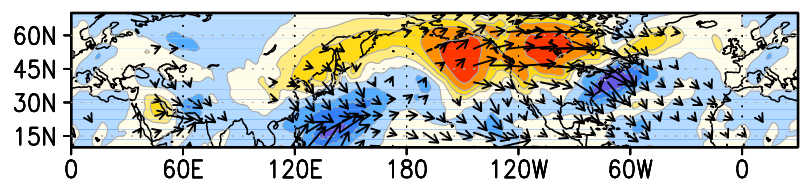

(c) Wave Activity Flux 18JAN2009

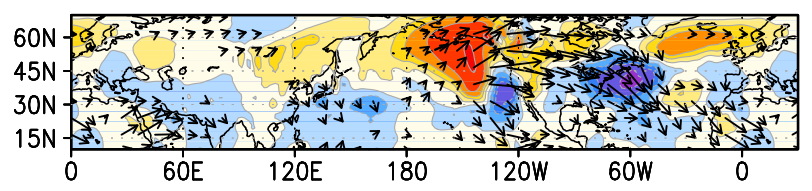

(d) Wave Activity Flux 21JAN2009

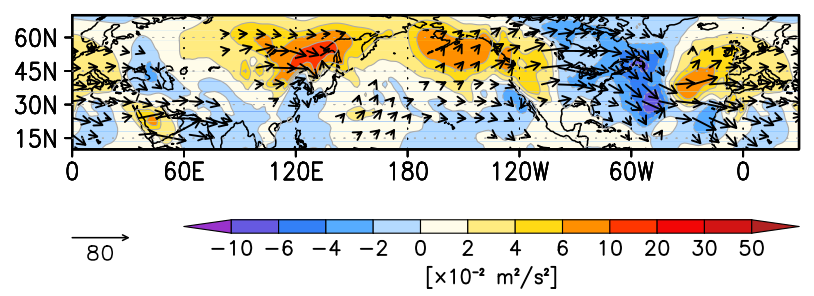

Fig. 11. Maps of the horizontal component of Plumb's (1985) 3-D wave activity flux (vectors; $\mathrm{m}^{2} \mathrm{~s}^{-2}$ ) and vertical component (color shading; $\mathrm{m}^{2} \mathrm{~s}^{-2}$ ) averaged between 125 and $100 \mathrm{hPa}$ on (a) $12 \mathrm{Jan}$ uary 2009, (b) 15 January 2009, (c) 18 January 2009, and (d) 21 January 2009. Vectors and colors are multiplied by $\cos \phi$.

Because the mean westerly flow extends to the tropical upper troposphere over the eastern Pacific and Atlantic during the boreal winter and spring (referred to as the "westerly duct"), the equatorward-propagating waves are able to enter the tropics (e.g., Webster and Holton, 1982; Kiladis and Weickmann, 1997). Harada et al. (2010) showed that wave activity over Alaska developed and intensified wave-2 structure in the northern high-latitudes during 15-20 January, and suggested that it played an important role in the SSW that occurred during January 2009. Thus, wave activity over Alaska has two roles; the equatorward EP flux between 125 and $100 \mathrm{hPa}$ entering the tropics caused tropical upwelling between 150 and $100 \mathrm{hPa}$, and the upward EP flux in the extratropics caused the SSW event. 

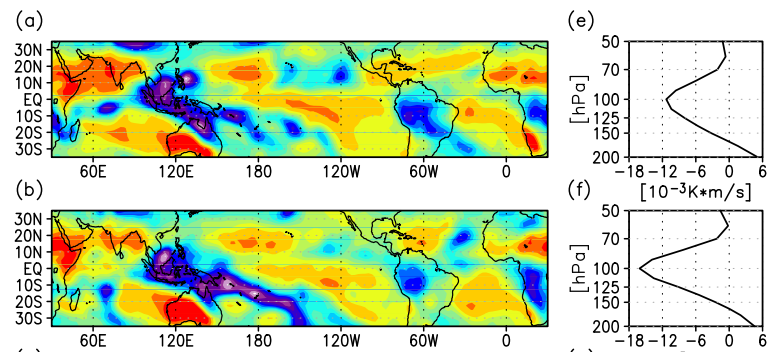

(c)
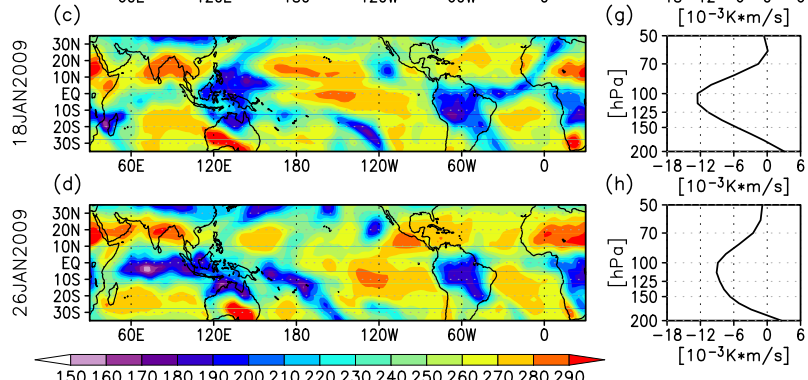

150160170180190200210220230240250260270280290

Fig. 12. (left) Maps of OLR $\left(\mathrm{W} \mathrm{m}^{-2}\right)$ and (right) vertical profiles of the vertical heat flux $\overline{w^{\prime} \theta^{\prime}}\left(\mathrm{K} \mathrm{m} \mathrm{s}^{-1}\right)$ averaged over $10^{\circ} \mathrm{S}-10^{\circ} \mathrm{N}$. (a, e) 2 January 2009, (b, f) 10 January 2009, (c, g) 18 January 2009, and (d, h) 26 January 2009. Data are smoothed using a 5-day running average.

\section{Discussion}

\subsection{Tropical convection}

In Sect. 3, we reported that vertical convergence of the vertical heat flux, $-\rho_{0}^{-1} \partial\left(\rho_{0} \overline{w^{\prime} \theta^{\prime}}\right) / \partial z$, resulted in reduced heating in the tropical uppermost troposphere from 12 to 26 January. The vertical heat flux is strongly linked to localized convection around the western tropical Pacific. Yoshida and Yamazaki (2010) suggested that the concentration of localized convection, such as the deep convection in the tropical western Pacific, warms the tropical uppermost troposphere and cools the upper TTL via vertical convergence of the vertical heat flux.

Figure 12 shows the time evolution of OLR and the vertical heat flux $\overline{w^{\prime} \theta^{\prime}}$ in the tropics. Before the SSW event, convection is gradually concentrated and intensified in the SPCZ, and negative value of the vertical heat flux is amplified at around $100 \mathrm{hPa}$ (Fig. 12a, b, e, f). The strong negative value of the vertical heat flux results in enhanced divergence in the lowermost stratosphere and enhanced convergence in the tropical uppermost troposphere. With the onset of the SSW event, convection is observed to decay near the tropical western Pacific and to intensify over tropical South America (Fig. 12c). At the same time, the negative value of the $100 \mathrm{hPa}$ vertical heat flux decays, resulting in weakened heating in the tropical uppermost troposphere (Fig. 12g). Subsequently, the more tropical convection extends zonally, the greater the degree that the negative value of the $100 \mathrm{hPa}$ ver-
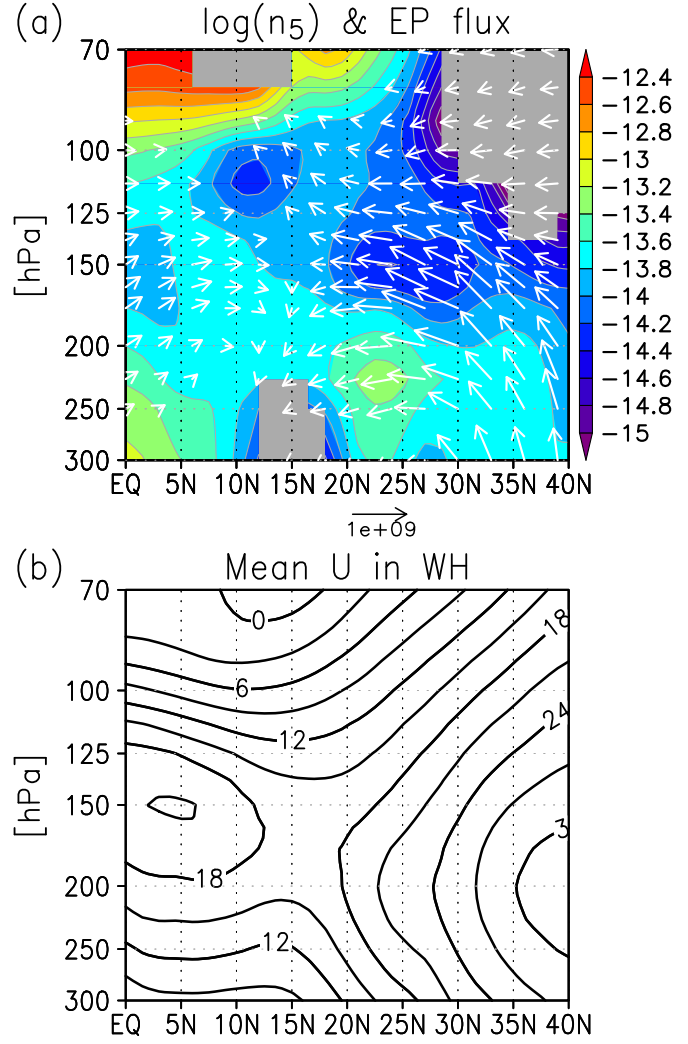

Fig. 13. (a) Latitude-altitude section of refractive index for stationary waves in zonal wavenumber 5 in the Western Hemisphere (color shading). Vectors denote the EP flux $\left(\mathrm{m}^{3} \mathrm{~s}^{-2}\right)$ on 18 January. (b) Latitude-altitude section of western hemispheric mean zonal wind $\left(\mathrm{m} \mathrm{s}^{-1}\right)$. Data averaged from 10 to 17 January are used to calculate the refractive index and the zonal wind. The refractive index is expressed by a logarithmic unit; imaginary values of the refractive index are masked. The EP flux is divided by the reference density, and the vertical component of the EP flux is multiplied by 300 .

tical heat flux diminishes (Fig. 12d, h). This result corresponds to the decay of heating by vertical convergence of the vertical heat flux in the tropical uppermost troposphere. The time evolution of convection is consistent with variations in vertical convergence of the vertical heat flux in the tropical uppermost troposphere.

Our results accord with several studies. Ahead of the cyclonic anomaly in the westerly duct, ascent occurs and static stability is reduced, which is consistent with the interpretation that equatorward-propagating waves force the convection (Kiladis, 1998; Matthews and Kiladis, 2000). In fact, the region in which the equatorward-propagating waves enter appears to generate a lower OLR (see Figs. 11 and 12). Hence, during the SSW event, the equatorward-propagating wave activity may cause not only circulation change in the TTL, but convection change. Further study is required on this topic. 


\subsection{Wave propagation toward the tropics}

The results presented in Sects. 4 and 5 indicate that wave propagation originating over Alaska has an influence on tropical ascent in the uppermost troposphere on 18 January. To generate tropical ascent in the uppermost troposphere, dissipation of the waves must have its maximum above the uppermost troposphere. To investigate why the waves propagate toward the tropical lowermost stratosphere, we calculated the refractive index for a stationary wave of zonal wavenumber 5, based on the mean field of the Western Hemisphere averaged from 10 to 17 January (Fig. 13a). Because of the small scale of the waves propagating to the tropics, the Western Hemisphere may be regarded as the background. Equatorward EP flux from the mid-latitude troposphere splits into two directions: toward the tropical lowermost stratosphere and toward the subtropics at around $250 \mathrm{hPa}$. Because these regions have a high refractive index, the equatorward-propagating waves change in direction and dissipate in the lowermost stratosphere at around $15^{\circ} \mathrm{N}$. At this time, the westerlies weaken with height in the TTL of the Western Hemisphere (Fig. 13b). Therefore, the tropical lowermost stratosphere has a high refractive index. Kiladis (1998) suggested that wave activity becomes more vertically constrained and propagates into the stratosphere as it moves equatorward through the subtropics, because the westerly weakens with height in the westerly duct.

\section{Summary}

In a study of the major stratospheric sudden warming (SSW) event of January 2009, we analyzed the temperature change and its mechanism in the tropics, focusing on the TTL, yielding the following main findings.

1. During the SSW event, wave forcing, especially by meridional eddy heat flux (first vertical component of the EP flux $F_{1}^{(z)}$ ), in the northern hemispheric stratosphere strongly induced tropical ascent in the stratosphere. However, the stratospheric wave forcing induced only weak upwelling in the tropics below $100 \mathrm{hPa}$.

2. On 18 January, at the onset of the SSW event, tropical ascent was the main contributor to cooling in the tropics between 150 and $100 \mathrm{hPa}$. Subsequently, vertical convergence of the vertical heat flux $\overline{w^{\prime} \theta^{\prime}}$, which is closely tied to the convection structure, resulted in a gradual decrease in heating and temperature in the tropical uppermost troposphere.

3. Residual mean vertical wind calculated by the transformed Eulerian mean model indicates that the wave dissipation around $15^{\circ} \mathrm{N}, 100 \mathrm{hPa}$ was the main driver of tropical ascent between 150 and $100 \mathrm{hPa}$ on around 18 January.
4. Equatorward-propagating waves at around $100 \mathrm{hPa}$, which had same source region with the upwardpropagating waves that caused the SSW event, traveled from Alaska to the tropical areas of eastern South America and eastern Africa, entered the tropical lowermost stratosphere, and dissipation of the waves drove the tropical upwelling between 150 and $100 \mathrm{hPa}$ on around 18 January.

Acknowledgements. We thank Y. Kuroda for useful discussions. We also thank anonymous reviewers for helpful comments. Interpolated OLR data were obtained from the Web site of NOAA/OAR/ESRL PSD, Boulder, Colorado, USA (http://www.esrl.noaa.gov/psd/).

Edited by: P. Haynes

\section{References}

Andrews, D. G., Holton, J. R., and Leovy, C. B.: Middle Atmosphere Dynamics, Elsevier, New York, 489 pp., 1987.

Fueglistaler, S., Bonazzola, M., Haynes, P. H., and Peter, T.: Stratospheric water vapor predicted from the Lagrangian temperature history of air entering the stratosphere in the tropics, J. Geophys. Res., 110, D08107, doi:10.1029/2004JD005516, 2005.

Fueglistaler, S., Dessler, A. E., Dunkerton, T. J., Folkins, I., Fu, Q., and Mote, P. W.: Tropical tropopause layer, Rev. Geophys., 47, RG1004, doi:10.1029/2008RG000267, 2009.

Harada, Y, Goto, A., Hasegawa, H., Fujikawa, N., Naoe, H., and Hirooka, T.: A Major Stratospheric Sudden Warming Event in January 2009, J. Atmos. Sci., 67, 2052-2069, doi:10.1175/2009JAS3320.1, 2010.

Hatsushika, H. and Yamazaki, K.: Stratospheric drain over Indonesia and dehydration within the tropical tropopause layer diagnosed by air parcel trajectories, J. Geophys. Res., 108(D19), 4610, doi:10.1029/2002JD002986, 2003.

Haynes, P. H. and Shepherd, T. G.: The importance of surface pressure changes in the response of the atmosphere to zonallysymmetric thermal and mechanical forcing, Q. J. Roy. Meteorol. Soc., 115, 1181-1208, doi:10.1002/qj.49711549002, 1989.

Haynes, P. H., Marks, C. J., McIntyre, M. E., Shepherd, T. G., and Shine, K. P.: On the "downward control" of extratropical diabatic circulation by eddy-induced mean zonal forces, J. Atmos. Sci., 48, 651-678, 1991.

Highwood, E. J. and Hoskins, B. J.: The tropical tropopause, Q. J. Roy. Meteorol. Soc., 124, 1579-1604, doi:10.1002/qj.49712454911, 1998.

Holton, J. R. and Gettleman, A.: Horizontal transport and the dehydration of the stratosphere, Geophys. Res. Lett., 28, 2799-2802, doi:10.1029/2001GL013148, 2001.

Holton, J. R., Haynes, P. H., McIntyre, M. E., Douglass, A. R., Rood, R. B., and Pfister, L.: Stratospheric-troposphere exchange, Rev. Geophys., 33, 403-439, 1995.

$\mathrm{Hu}, \mathrm{Y}$. and Tung, K. K.: Interannual and Decadal Variations of Planetary Wave Activity, Stratospheric Cooling, and Northern Hemisphere Annular Mode, J. Climate, 15, 1659-1673, 2002.

Kerr-Munslow, A. M. and Norton, W. A.: Tropical wave driving of the annual cycle in tropical tropopause temperatures. 
Part I: ECMWF analyses, J. Atmos. Sci., 63, 1410-1419, doi:10.1175/JAS3697.1, 2006.

Kiladis, G. N.: An observational study of Rossby waves linked to convection over the eastern tropical Pacific, J. Atmos. Sci., 55, 321-339, 1998.

Kiladis, G. N. and Weickmann, K. M.: Horizontal structure and seasonality of large-scale circulations associated with submonthly tropical convection, Mon. Weather Rev., 125, 1997-2013, 1997.

Kodera, K.: Influence of stratospheric sudden warming on the equatorial troposphere, Geophys. Res. Lett., 33, L06804, doi:10.1029/2005GL024510, 2006.

Kuroda, Y.: Effect of stratospheric sudden warming and vortex intensification on the tropospheric climate, J. Geophys. Res., 113, D15110, doi:10.1029/2007JD009550, 2008.

Kuroda, Y. and Kodera, K.: Role of the Polar-night Jet Oscillation on the formation of the Arctic Oscillation in the Northern Hemisphere winter, J. Geophys. Res., 109, D11112, doi:10.1029/2003JD004123, 2004.

Liebmann, B. and Smith, C.A.: Description of a Complete (Interpolated) Outgoing Longwave Radiation Dataset, B. Am. Meteor. Soc., 77, 1275-1277, 1996.

Manney, G. L., Schwartz, M. J., Krüger, K., Santee, M. L., Pawson, S., Lee, J. N., Daffer, W. H., Fuller, R. A., and Livesey, N. J.: Aura Microwave Limb Sounder observations of dynamics and transport during the record-breaking 2009 Arctic stratospheric major warming, Geophys. Res. Lett., 36, L12815, doi:10.1029/2009GL038586, 2009.

Matsuno, T.: Vertical propagation of stationary planetary waves in the winter Northern Hemisphere, J. Atmos. Sci., 27, 871-883, 1970.

Matsuno, T.: A dynamical model of the stratospheric sudden warming, J. Atmos. Sci., 28, 1479-1494, 1971.
Matthews, A. J. and Kiladis, G. N.: A Model of Rossby Waves Linked to Submonthly Convection over the Eastern Tropical Pacific, J. Atmos. Sci., 57, 3785-3798, 2000.

Norton, W. A.: Tropical wave driving of the annual cycle in tropical tropopause temperatures. Part II: Model results, J. Atmos. Sci., 63, 1420-1431, doi:10.1175/JAS3698.1, 2006.

Plumb, R. A.: Zonally symmetric Hough modes and meridional circulations in the middle atmosphere, J. Atmos. Sci., 39, 983991, 1982.

Plumb, R. A.: On the Three-Dimensional Propagation of Stationary Waves, J. Atmos. Sci., 42, 217-229, 1985.

Plumb, R. A. and Eluszkiewicz, J.: The Brewer-Dobson circulation: Dynamics of the tropical upwelling, J. Atmos. Sci., 56, 868-890, 1999.

Simmons, A. J., Uppala, S. M., Dee, D., and Kobayashi, S.: ERAInterim: New ECMWF reanalysis product from 1989 onwards, ECMWF Newsl., 110, 25-35, 2006.

Uppala, S. M., Dee, D., Kobayashi, S., Berrisford, P., and Simmons, A. J.: Towards a climate data assimilation system: Status update of ERA-Interim, ECMWF Newsl., 115, 12-18, 2008.

Webster, P. J. and Holton, J. R.: Cross-equatorial response to middle-latitude forcing with a latitudinally and zonally nonuniform basic state, J. Atmos. Sci., 39, 722-733, 1982.

Yoshida, K. and Yamazaki, K.: Role of vertical eddy heat flux in the response of tropical tropopause temperature to changes in tropical sea surface temperature, J. Geophys. Res., 115, D01108, doi:10.1029/2009JD012783, 2010.

Yulaeva, E., Holton, J. R., and Wallace, J. M.: On the cause of the annual cycle in tropical lower-stratospheric temperatures, J. Atmos. Sci., 51, 169-174, doi:10.1175/15200469(1994)051<0169:OTCOTA>2.0.CO;2, 1994. 